\title{
De la memoria a las memorias: Una reflexión teórico-metodológica en torno a la relación entre memoria y educación en derechos humanos ${ }^{1}$
}

\author{
From memory to memories: A theoretical-methodological reflection among the \\ relationship between memory on human rights education
}

\author{
Noemí Pérez Martínez² \\ Pérez M. Noemí \\ miradas $\mathrm{N}^{\circ} 1$ - 2018 ISSN digital $\mathrm{N}^{\circ}$ 2539-3812 Págs 96 - 115 \\ Recepción: Agosto 15 de 2017 \\ Aprobación: Marzo 9 de 2018 \\ Publicación: Junio 29 de 2018
}

\section{Resumen}

Este artículo corresponde a una reflexión teórica y metodológica alrededor de la educación en derechos humanos $(\mathrm{EDH})$ y la memoria, como elemento fundamental en los procesos de educación en contextos de violencia, política y sociedades con democracia restringida. Esta reflexión es producto de la revisión teórica sobre EDH y memoria, aspectos que se constituyen en columna vertebral del proyecto de tesis doctoral titulado Educación en/ para los derechos humanos desde la perspectiva de la memoria. Un análisis de ocho experiencias educativas en instituciones públicas de Santiago de Chile y Bogotá. El propósito es presentar la categoría memoria en sus diversas acepciones y perspectivas, mostrando su fuerte relación con la EDH.

Palabras claves: memoria, memoria social, pedagogía de la memoria, educación en derechos humanos.

1 Este artículo presenta una reflexión teórica y metodológica alrededor de las categorías de educación en derechos humanos y la memoria, eje central del proyecto de tesis doctoral titulado Memoria, subjetividad política, ciudadanía y derechos humanos. Análisis de ocho experiencias de educación en/para los derechos humanos en escuelas públicas de Bogotá y Santiago de Chile 2005-2015.

2 Docente catedrática de la Universidad Pedagógica Nacional; docente de la Secretaría de Educación de Bogotá; estudiante del Doctorado Interinstitucional en Educación DIE (Universidad Pedagógica Nacional).

noemip2001@yahoo.com 
De la memoria a las memorias: Una reflexión teórico-metodológica en torno a la relación entre memoria y educación en derechos humanos.

\section{Abstract}

The current article is a theoretical and methodological reflection among human rights education (EDH for its acronym in Spanish; HRE in English) and memory, as significant element on education processes in contexts of violence, politics and societies with restricted democracy. This reflection is the product of the theoretical review of HRE and memory, conceptions which constitute the central axis of the doctoral thesis project entitled Education in/for human rights from the perspective of memory. An analysis of eight educational experiences in public institutions in Santiago de Chile and Bogotá. The purpose is to present the category of memory in its different meanings and perspectives, showing its strong relation with HRE.

Keywords: Memory, Social memory, Pedagogy of Memory, Human Rights Education.

\section{Introducción}

En contextos marcados por fuertes vulneraciones de los derechos humanos a raíz de la violencia política que envolvió a gran parte de la región latinoamericana durante la Guerra Fría y que se materializó en dictaduras y democracia restringida, han venido cobrando importancia los procesos de educación en derechos humanos $(\mathrm{EDH})$, que apuntan a la concientización y comprensión de las realidades violentas en que se ha sumido la población durante varias décadas. Los actos de barbarie vividos han dejado secuelas físicas, psicológicas y culturales que se constituyen en verdaderas heridas de guerra. Este escenario obliga a buscar formas de intervención masiva tendientes a revertir la situación, transformando una cultura social del miedo, de la desconfianza y del deseo de venganza, en una cultura democrática y de paz, base para la reconstrucción del tejido social y la construcción de una cultura democrática.

En esta ardua tarea ocupa un lugar muy importante la memoria, por cuanto el relato acallado de las víctimas se constituye en una voz potente para salir de la amnesia en que se ha querido sumir a la población en épocas de violencia y conflicto político. Las voces de los que no han tenido voz contribuyen de manera notable a gritar "basta ya". Es un "basta ya" al que se adhiera una sociedad entera, el cual solo se logra mediante la visibilización y comprensión de los procesos históricos vividos en la historia reciente de nuestro continente.

En ese sentido, los procesos de EDH deben trascender el simple reconocimiento de mecanismos e instrumentos de protección de derechos humanos, los cuales son vistos como letra muerta en una sociedad como la colombiana en la que la noticia diaria es la exclusión política, la eliminación física del adversario y el desplazamiento de los territorios ancestrales, en un país que cumple su ritual electoral en los periodos indicados mediante un ejercicio del voto sin conciencia ciudadana.

La EDH tiene gran relevancia en contextos de alta vulnerabilidad como Colombia y Chile, países donde su larga historia de violencia política ha dejado miles y miles de víctimas que claman por el esclarecimiento de la verdad y la aplicación de justicia y reparación. En esta búsqueda, la memoria ocupa un lugar imprescindible, pues es a través de ella que se logra la cohesión social 
y se cimenta un camino hacia la verdad y la restitución de los derechos. Es por ello que consideramos como elemento fundamental de esta categoría en la investigación.

La memoria, o mejor, las memorias, se conforman en el ámbito individual y se proyectan al escenario social y político en donde sucedió el acontecimiento que es susceptible de recordación; así, los recuerdos cobran sentido en la medida que existen unos marcos sociales que les dan sentido. En este orden de ideas, es importante realizar precisiones acerca de los diversos conceptos que se han venido configurando en el campo epistemológico.

\section{Memoria colectiva, memoria social y memoria política}

Para la conceptualización de estas tres categorías de memoria, es clave el trabajo realizado por Maurice Halbwachs, quien estableció claras diferencias entre memoria social, memoria colectiva y memoria histórica. La memoria colectiva es una de las categorías de mayor uso en las investigaciones tanto sociales como históricas. Para Halbwachs (2011), los recuerdos se construyen a partir de la confrontación de testimonios de quienes han vivido las experiencias o lo han transmitido a las nuevas generaciones mediante «el relato vivo de los primeros actores y espectadores» (p. 84). De tal manera, la memoria se configura en la cotidianidad, y se transforma o adquiere ciertos matices que dependen de las diversas interacciones de los sujetos que comparten una situación o un pasado común. En palabras de Halbwachs:

La memoria colectiva es un cuadro de parecidos, y es na- tural que se dé cuenta de que el grupo siga y haya seguido igual, porque fija su atención en el grupo, y lo que ha cambiado son las relaciones $\mathrm{o}$ contactos del grupo con los demás. Como el grupo siempre es el mismo, los cambios han de notarse: los cambios, es decir, los acontecimientos que se producen en el grupo se resuelven por sí mismos como similitudes, ya que parecen tener la misión de desarrollar en diversos aspectos un contenido idéntico, es decir diversos rasgos fundamentales del grupo en sí (p. 92).

Desde la antropología, la memoria colectiva se considera una noción difusa, carente de fundamentos teóricos sólidos. Para Joel Candau (2006):

(...) la memoria colectiva es más la suma de los olvidos que la suma de los recuerdos pues, ante todo y esencialmente, estos son el resultado de una reelaboración individual, tanto que aquellos tienen en común, precisamente, el haber sido olvidados (p. 64).

Candau propone una taxonomía de las diferentes manifestaciones de la memoria:

1. Memoria de bajo nivel (protomemoria): constituye el saber y la experiencia inmediata, las cuales comparten los miembros de un grupo. $\mathrm{La}$ protomemoria es una memoria 
imperceptible, que agita al sujeto sin que este lo note, por ejemplo, cuando un bebé aprende a caminar.

2. Memoria (o de alto nivel): es una memoria de recuerdo o de reconocimiento, una convocatoria deliberada o una evocación involuntaria de recuerdos, ya sea autobiográficos o de saberes, creencias, sensaciones, etc.

3. Metamemoria: por un lado, es una representación que cada individuo hace de su propia memoria y por otro, lo que él dice sobre ella.

Cuando nos referimos a la memoria individual, los tres términos tienen una gran aceptación; pero cuando nos referimos a una colectiva, solo se puede hablar de memoria de alto nivel y metamemoria, ya que es imposible hablar de una protomemoria que sea igual en todos los individuos. Al respecto, Candau (2001) señala también que la expresión de memoria colectiva no puede tomarse como una facultad, ya que la única facultad de memoria que puede certificarse es la individual y solo puede hablarse de memoria colectiva como representación. Para el autor: «La memoria colectiva es una forma de meta memoria, es decir, un enunciado que los miembros de un grupo quieren producir acerca de una memoria supuestamente común a todos los miembros de ese grupo» (pp. 19-22).

A su vez, Pierre Nora (s.f.) retoman lo que Rodríguez plantea que la memoria colectiva es «el recuerdo o conjunto de recuerdos, conscientes o no, de una experiencia vivida y/o mitificada por una colectividad viviente, de cuya identidad el pasado forma parte integrante» (Nora, s.f., p. 4).
Por su parte, Noiriel y Cuesta reconocen que Rodríguez (2008) no plantean un concepto preciso acerca de la memoria colectiva, sino que:

\section{(...) los autores consideran} una serie de características: es acumulativa, cada experiencia se organiza en una secuencia temporal que se transforma constantemente en función del presente de los grupos, lo que permite hablar de una sedimentación y de una multiplicidad de memorias en reestructuración constante; es concreta, sensible $y$ subjetiva, en tanto pretende mantener, perennizar la identidad colectiva del grupo, exaltando los elementos comunes de sus miembros, es selectiva, limitada, frágil $y$ manipulada, por efecto del tiempo trascurrido, por la imposibilidad de retener todos los recuerdos y por efecto de los intereses del presente ( $\mathrm{p}$. 69).

Es reciente el estudio de la memoria social relacionada con los procesos sociales o colectivos, pues se ubica entre finales del siglo XIX y comienzos del XX. Halbwachs (2004) la ubica en estrecha relación con los desarrollos sociales, políticos y culturales, es decir, con las costumbres de los grupos sociales, y establece una estrecha relación entre el recuerdo individual, el social y el colectivo. Por ello, considera que toda memoria es social. Al respecto, Halbwachs plantea que: No hay memoria que no sea social. Cada yo está conectado a un nosotros por lo que su 
recuerdo se forja en la interacción con el grupo o grupos de pertenencia (la familia, la comunidad escolar, la profesión). La memoria individual de cada persona está inmersa en un horizonte de interpretación sociocultural que determina y también posibilita su propia actividad de recuerdo. Lo anterior es lo que Halbwachs denominó los marcos sociales de la memoria, estos son los que determinan el recuerdo, en ese sentido el olvido no sería más que el debilitamiento de ese marco social y la desaparición o transformación del contexto vivido socialmente.

Para Halbwachs (2004):

(...) la necesidad de estar limitado a la temporalidad de una vida determinada [en la cual se conforma la memoria colectiva], se opone a las exigencias sociales de unidad como ésta se opone a la necesidad social de continuidad. Son estas las razones por las que la sociedad tiende a separar de su memoria todo lo que podría separar a los individuos, alejar los grupos los unos de los otros, y que en cada época ella modifica sus recuerdos para reajustarlos con las condiciones variables de su equilibrio (p. 336).

La emergencia de la categoría memoria política se ubica en los hechos de violencia política ocurridos en América Latina. Se centra especialmente en los casos de los países del Cono Sur y la implantación de regímenes dictatoriales, y en Colombia y el desarrollo del conflicto armado, ya que se refiere a los recuerdos suscitados a raíz de la violencia política y como estos recuerdos se llevan a la esfera de lo público. Es una categoría de menor difusión que las de memoria social, memoria colectiva o memoria histórica, tal vez porque muchas investigaciones involucran en la memoria social los hechos políticos. Sin embargo, Javier Alejandro Lifschitz ha dedicado varios artículos a la reflexión sobre esta categoría y establece claras diferencias con la memoria social y la memoria colectiva. Lifschitz plantea que la distinción entre memoria social y memoria política reside en el tipo de vínculo social que ambas establecen. Al respecto, el autor aclara que:

Nuestra hipótesis de trabajo es que, si la memoria social está asociada a vínculos sociales espontáneos, la memoria política lo está a acciones intencionales. Para comprender lo que está en juego en el carácter intencional de la memoria política debemos considerar que la memoria, sea social o política, es una acción mediada por el lenguaje. Esto justifica que nos desplacemos de la teoría de la acción social, en un sentido durkhemiano, hacia a la teoría de la acción comunicativa (Habermas, (citado por Lifschitz, 2012, p. 7).

Se menciona que la memoria política hace referencia a los hechos políticos; sin embargo, es importante aclarar que la memoria política no se reduce a las políticas del Estado única y exclusivamente, sino que incluye a aquellos actores sociales que guardan relación con hechos por lo 
De la memoria a las memorias: Una reflexión teórico-metodológica en torno a la relación entre memoria y educación en derechos humanos.

general vinculados al terrorismo de Estado y que pretenden visibilizar sus memorias. Al respecto, es evidente que en las últimas décadas surgieron nuevos agentes, instituciones y prácticas vinculados a la memoria sobre el terrorismo de Estado, como las Madres de Plaza de Mayo, los testimonios, los movimientos de derechos humanos, las comisiones de verdad y/o de justicia, los centros de memoria, la instauración de monumentos a la memoria de víctimas y otros. Para Lifschitz (2012):

Estas memorias, que se visibilizan en marchas, emplazamiento de monumentos, juicios y demás actos y acciones estratégicas que consiste en que tanto individuos como grupos sitúen en la esfera pública sus acciones, sentimientos y dolores, en el mayor de los casos para confrontar al o a los autores de las violaciones de derechos. En la esfera pública los participantes "asumen posiciones" y "uniones potenciales" de diálogo o de opinión. La esfera pública no es una institución, ni una organización, pues no constituye una estructura normativa capaz de diferenciar competencias $\mathrm{y}$ roles sociales. Tampoco es un sistema, porque se caracteriza por tener "horizontes abiertos, permeables y desplazables". Es más bien una red adecuada para la comunicación de contenidos, toma de posiciones y opiniones, y está asociada tanto a la acción de movimientos sociales, como a ámbitos considerados privados, donde a través los medios de comunicación, por ejemplo, los sujetos son convocados a tomar posicionamientos políticos. En suma, hablar sobre memoria política es reconocer intencionalidades estratégicas y esto se evidencia en los procesos de construcción de las memorias nacionales ( $\mathrm{p}$. 16).

\section{Memoria histórica}

Halbwachs (2011) empleó la categoría memoria histórica para establecer diferencias entre la memoria autobiográfica y la memoria histórica. La primera se refiere a los hechos que componen los recuerdos individuales y se constituye a partir de la experiencia que cada individuo tiene con su grupo de pertenencia; mientras que la segunda alude a una memoria histórica, conformada por recuerdos transmitidos entre distintas generaciones que no tuvieron contacto con los hechos que se rememoran, pero que tienen incidencia en la pertenencia de los individuos a su grupo. A decir de Halbwachs, la memoria histórica es la memoria prestada, de acontecimientos del pasado, que el sujeto no ha experimentado personalmente y a la que llega mediante los documentos de diverso tipo. La memoria histórica se mantiene viva gracias a las conmemoraciones, que a su vez sirven para reforzar sus lazos de identidad con los grupos a los que pertenece ese sujeto. Esta historia es complementaria de la historia escrita; se perpetúa y renueva con el paso del tiempo en relaciones intergeneracionales, en "entornos cercanos", y en las referencias 
temporales que ofrecen los acontecimientos nacionales a quienes hacen parte de un país. Es lo que Halbwachs denomina los "marcos lejanos".

Con relación a Rodríguez (2013) se observa:

Según Ignacio Peiró Martín existen tres momentos de convergencia y enfrentamiento de la memoria histórica en el ámbito de la historiografía: el primero desde principios de los años sesenta como fuente de la historia en la historia desde abajo, la historia social, la historia oral y la memoria. La memoria histórica en el marco de este tipo de investigaciones abrió una ruta de trabajos históricos asociados a las identidades y la subjetividad en el marco de posiciones éticas que articulan la condición de protagonista social del historiador y su responsabilidad profesional (p. 49).

\section{Memoria e historia: el debate}

Si bien es cierto que la memoria se ha convertido en una preocupación dentro de las sociedades contemporáneas marcadas por la violencia política - sociedades que claman por el esclarecimiento de hechos atroces que el discurso de la historia oficial se empeña en ocultar y tergiversar a su acomodo-, es importante considerar que este hecho ha redundado en debates en el campo de la historia sobre el lugar de la memoria y las fronteras entre memoria e historia.
En la investigación, se asume que la memoria cobra sentido en cuanto hace parte de la historia reciente o del tiempo presente, ya que en ningún momento se puede hablar de unas memorias desligadas de un contexto histórico. En este orden de ideas, resulta fundamental plantear algunos elementos importantes del debate entre memoria e historia. En primer lugar, se destacan las pretensiones de objetividad, que provenientes del positivismo, postulan la toma de distancia entre el objeto investigado y el investigador, razón por la cual solo es factible si se ubica en un pasado allende los 50 años. Es por ello que las investigaciones y análisis de hechos recientes de los que se ocupa la memoria presentan dificultades no solo de objetividad, sino que también admiten como problemático el uso de las fuentes sobre las que se sustentan. Así, bajo el argumento de ser testimoniales, se presupone que estas fuentes están atrapadas en la subjetividad, a lo cual se suma el elemento hermenéutico que comporta abordar procesos históricos inacabados en pleno movimiento, configurando una circunstancia que ubicaría a la memoria fuera de los estatutos disciplinares de la historia y más cercana a otros campos disciplinares, como el sociológico, antropológico o periodístico (Bresciano, 2010).

En esta dirección, se encuentra que se le otorga una mayor jerarquía a la historia que a la memoria (Rioux, 1988). Otros pensadores, como Ricoeur (2008) y Dosse (2012, citado por Herrera y Pertuz, 2016), consideran que la temporalidad se constituye en un hilo común entre historia y memoria, y que, por lo tanto, la relación entre ellas es de complementariedad antes que de exclusión o de asimilación. Por su parte, François Hartog (2003) se refiere al 
asunto señalando que cada uno de estos campos del saber corresponde a un régimen de historicidad. En la modernidad, centrada en la idea de progreso, la historia se encontraba al servicio del Estado nacional y el pasado era la base fundamental para construir el futuro; por lo tanto, la historia ocupa un lugar de gran relevancia. En palabras de Herrera y Pertuz (2016):

En la contemporaneidad especialmente a partir de 2001, según Hartog (2003) se configura otra historicidad, en donde el presentismo ocupa un lugar destacado y el futuro no depende del pasado, "la memoria ocupa un lugar preeminente. Obviamente, estos dos regímenes de historicidad coexisten, sin que necesariamente el emergente haya conseguido desalojar el otro por completo" (p. 30).

La emergencia de la memoria plantea, entonces, una serie de retos para la investigación. En este acercamiento con la historia, buscando así incursionar en la dimensión humana de la historia y en el reconocimiento de sujetos y actores sociales que durante mucho tiempo han estado excluidos de la historia oficial, y que ahora pugnan por hacer parte de la memoria histórica.

Como resultado de estas tensiones y discusiones entre historia y memoria, se pone en escena la historia como presentepasado o historia vivida. Es lo que Dosse (2012) denominó "historia del tiempo presente": educación en derechos humanos.

La historia del tiempo presente está en el cruce del presente $\mathrm{y}$ del largo término. Ella plantea el problema de saber cómo el presente está inscrito, construido en el tiempo (...). Por mi parte defenderé la idea de una verdadera singularidad de la noción de historia del tiempo presente que reside en la contemporaneidad de lo no contemporáneo, en el espesor temporal del "espacio de la experiencia", en el presente del pasado encorpado ( $\mathrm{p}$. 119).

Y en el mismo sentido, Herrera y Pertuz (2016) observan que:
(...) la categoría de tiempo presente nos sirve como fun- damento epistemológico para el abordaje de las problemáti- cas relacionadas con el pasado reciente y la serie de dilemas con respecto a su transmisión, enseñanza y aprendizaje, en escenarios en los que tiene lu- gar la formación de sujetos y la configuración de subjetivi- dades (p. 32).

La emergencia de las memorias en la sociedad contemporánea brinda la oportunidad de conocer los hechos traumáticos que afectaron a una gran parte de la humanidad a las generaciones que no han pasado por los horrores de la guerra, el genocidio, las dictaduras, las desapariciones forzadas y las ejecuciones extrajudiciales, al tiempo que les plantea un desafío ético y político. Estas circunstancias, que 
han golpeado a amplios sectores de la población, impulsan a quienes sufren por el dolor de haber perdido a sus seres queridos, a clamar verdad, justicia, reparación y no repetición. Con ello, se cumpliría el deber de la memoria, que según Augé (1998), presenta dos aspectos: por un lado, el recuerdo, y por otro, la vigilancia. La vigilancia como actualización del recuerdo y como un esfuerzo por imaginar en el presente lo que podrá semejarse al pasado, por recordar el pasado como un presente. Esta vigilancia es atención y cuidado tanto del presente como del futuro.

\section{Tramitación del pasado. Pedagogía de la memoria}

Para cumplir con ese deber de memoria ejemplar, se hace presente el interrogante: ¿de qué manera tramitar el pasado doloroso a las nuevas generaciones, apostando por la comprensión de los procesos políticos y sociales que enmarcan la historia de una región o país? Es así como se plantea una pedagogía de la memoria, entendida por Bárcena y Melich (2011) como «una reflexión ética sobre la memoria como experiencia viva del tiempo, una reflexión sobre la transmisión del dolor y sobre una cultura que a menudo tiene sus propias narrativas de duelo y de sufrimiento» (p. 116). Dicha pedagogía está cruzada por un compromiso ético que conlleva la comprensión del dolor del otro como de un nosotros, llevándolo a niveles de empatía que hagan posible la imaginación y la recreación en la mente de quienes se acercan a ese pasado. No obstante, no se trata de ninguna clase de adoctrinamiento político ni ideológico, pues no se puede olvidar que aunque esos acontecimientos se comparten con una comunidad, suponen una experiencia subjetiva, íntima y privada.
La memoria puede tramitarse de diversas maneras, entre las cuales se destacan la escuela, los memoriales, los centros de memoria y los monumentos y museos. Cada uno de estos escenarios requiere de procesos de enseñabilidad y pedagogía que conlleven un acercamiento de las nuevas generaciones a los acontecimientos del pasado reciente, pero un acercamiento crítico y encaminado hacia la construcción de una ciudadanía empoderada y resuelta al ejercicio de los derechos humanos. En esa dirección, Rubio (2012) propone:

Se requiere la construcción de una pedagogía de la memoria que contribuya a la formación ciudadana, que abra su dimensión temporal en perspectiva vital (constitución de subjetividades) y que vincule dicha condición a una existencia política con sentido. La pedagogía que asuma dicha tarea debe orientar su enseñabilidad vislumbrando un futuro político que construya desde un horizonte que integre la historicidad de los hechos, la experiencia del pasado reciente, y la visión de comunidad sustentada por una ética abierta al otro (p. 390).

Esta pedagogía se centra en la comprensión del pasado reciente y cuenta con un horizonte pedagógico sustentado en tres aspectos: a) promover un aprendizaje de la convivencia política desde el sentido y cuidado del otro, desde la sensibilidad y la reflexión del dolor y la pérdida de vidas en la sociedad; b) promover un aprendizaje sobre la identidad como comunidad 
temporal de sentido, esto es, que considere el pasado reciente como sustrato de la existencia social, tanto del pasado como del presente, encaminado a la construcción de una memoria cívica, y c) la incorporación de la enseñanza de derechos humanos desde una perspectiva histórica y vital como fuente de reflexión de la condición de ciudadanía (Rubio, 2012).

Frente a las posibilidades y límites del ejercicio de una pedagogía de la memoria, la profesora Rubio (2012) plantea que:

\section{(...) una pedagogía de la me-} moria situada en estos marcos debería abrir nuevas tramas de posibilidad; revertir el orden formal del tiempo; dialogar críticamente con los relatos de la Historia; cuestionarse sobre los futuros prescritos; contrastarlos desde la contingencia con los deseos, volviendo su mirada al pasado para recuperar proyectos inconclusos, lo no dicho y lo olvidado (p. 392).

En este sentido, se trata de una pedagogía de la memoria que establece una relación muy cercana -incluso de dependenciaentre memoria e historia, relación que permitiría dejar de lado la rivalidad entre estos dos saberes y formas de investigar el pasado. $\mathrm{Y}$ es que tanto la memoria como la historia participan de un diálogo que invita, por un lado, a la historia a abrirse como vivencia social acontecida y narrable, y a la memoria, en calidad categoría ético-política, a tomar distancia del discurso presentista modernizador y naturalizador, para moverse hacia los conceptos disciplinares, apartándose de la idea de banalizar la experiencia del pasado, valorándola como fuente importante para la compresión y la narración del recuerdo.

Un desafío importante en la pedagogía de la memoria lo constituye el tratamiento de la categoría de víctima, toda vez que su testimonio es central en todo proceso de memoria. Ello implica asistir a una disputa por el posicionamiento del testimonio, el cual se ubica en un eterno presente, que deja en un segundo plano la narración histórica.

A propósito del sujeto víctima, acogido como pieza central en el estudio de la memoria y en la pedagogía de la memoria, es necesario mencionar que la emergencia de las víctimas como categoría histórica está unida al peso del presente. Al respecto Hartog (2012) indica:

El presente del drama que acaba de irrumpir o que irrumpió tiempo atrás pero que sigue siendo para la víctima su único presente. Puede ser un presente fijo o un presente que no pasa. Esta temporalidad propia de la víctima se inscribe muy bien en la configuración presentista en la que nos movemos hoy en día, o mejor, trabaja esta estructura y la refuerza (p. 15).

Esta emergencia de las víctimas ha impactadoen la configuración de la memoria pública y en las políticas de la memoria de los distintos países que han atravesado por conflictos políticos atroces, los cuales han dejado a su paso centenares de víctimas que 
deben ser tratadas como sujetos políticos y no como objetos de compasión. En esta tarea, la pedagogía de la memoria tiene un lugar muy destacado, pues el acercamiento y tratamiento de las víctimas debe superar su utilización como simples fuentes testimoniales, para vincularlas a procesos democráticos mediante la consolidación de una ciudadanía memorial que las lleve a consolidarse como sujetos y actores políticos activos, dentro una sociedad que comprende los conflictos y los tramita de forma pacífica, dentro de los marcos de la ciudadanía y el respeto de los derechos humanos.

\section{Políticas de la memoria}

Si bien es cierto que las acciones violentas producto del terrorismo de Estado en la época de la violencia política (en Chile, en el marco de la dictadura cívico-militar de Augusto Pinochet [1973-1990] y en Colombia, en el marco de un conflicto armado de más de 50 años [sus inicios se datan en 1964 con la conformación de las primeras guerrillas]) sembraron el miedo en gran parte de la población víctima y permearon todo el tejido social, también lo es que en medio del miedo y el terror producidos por las acciones represivas perpetradas por los protagonistas de esos conflictos, algunos sujetos ejercieron valientes labores de resistencia, que apuntaron al restablecimiento de la democracia y el ejercicio de la ciudadanía. Los hechos impulsaron la formulación de políticas que trazaron lineamientos en torno a la formación política y a la consolidación de una cultura política democrática desde finales de la década de 1980. Es el momento cuando se inician los procesos de transición democrática en el Cono Sur y en Colombia se inaugura el establecimiento de un orden constitucional menos restrictivo mediante la elaboración y puesta en marcha de la Constitución Política de 1991.

El resultado de este cambio de rumbo se traduce en fuertes presiones por parte de actores sociales y políticos (entre ellos, las organizaciones de víctimas y las organizaciones sociales defensoras de derechos humanos) para que el Estado asuma la tarea de esclarecer los crímenes de Estado, para que restaure el ejercicio de la justicia, y se comprometa con la reparación y no repetición. El efecto directo es la promulgación de políticas de la memoria que permitan tramitar de la mejor manera posible los abusos a los que fueron sometidas miles de personas que se constituyeron en víctimas.

Una de las funciones del Estado, en este nuevo contexto de emergencia del sujeto víctima, es tramitar los recuerdos y las memorias de los diversos sectores afectados; es decir, el Estado debe garantizar el derecho a la memoria, sumándose a sus funciones y deberes uno más: el "deber de la memoria". Para que pueda cumplir con esta nueva responsabilidad, resulta necesario que el Estado implemente políticas de la memoria, entendidas por Reyes, Muñoz y Vásquez (2013), citados por Herrera y Pertuz (2016), como «un campo dinámico y conflictivo en el cual la memoria se configura como dispositivo político» (p. 47). Estas nuevas políticas de la memoria quedan ligadas a las lógicas particulares de cada contexto político y encuentran relación con las características y dinámicas internas y con las políticas internacionales. Al respecto, Herrera y Pertuz (2016) reseñan: 
De la memoria a las memorias: Una reflexión teórico-metodológica en torno a la relación entre memoria y

Autores como Peris (2008), Vinyes (2009a y 2009 b), Richard (2010), Hartog (2012), han mostrado, apoyándose en Wieviorka (1998), el predominio de un escenario internacional en el cual las políticas de la memoria privilegian los aspectos consensuales y dan a la figura de la víctima y a su testimonio un lugar en el cual se hace mayor énfasis a los aspectos atinentes al individuo, a sus sufrimientos físicos y sicológicos, desdibujando los móviles históricos y las dimensiones sociales de la victimización (p. 48).

Lo anterior plantea la emergencia de una nueva persona: la víctima, figura que comporta una forma particular de ver y analizar los acontecimientos sociales y políticos, toda vez que los liga a un eterno presente, siempre fijo, que no se transforma. La emergencia de este interlocutor promueve profundos debates conceptuales sobre la objetividad y validez de una memoria basada en testimonios marcados por la subjetividad. Sobre el particular, Herrera y Pertuz (2016) observan:

De este modo, las memorias de las víctimas o entorno a las víctimas han alimentado el campo de la memoria pública y de las políticas de la memoria, en diversidad de formatos que abarcan desde el testimonio jurídico, hasta otro tipo de expresiones narrativas $y$ performativas que van desde la novela testimonial hasta el educación en derechos humanos.

cine, el teatro, las artes plásticas, expresiones que forman parte del legado social que debe ser trasmitido, apropiado y reelaborado por la sociedad, en sus distintos arcos generacionales (p. 50).

De forma sucinta, se presentan a continuación las políticas públicas elaboradas por Chile y Colombia, países sobre los que se centra la investigación. Stern (2000) considera que Chile ha pasado por distintas etapas de memorias sobre la dictadura. La primera, desarrollada entre 1973 y 1976, es la memoria como salvación. En esta etapa se plantea que el golpe militar constituyó la salvación de una dictadura marxista para el país. Luego, entre finales de la década del 70 e inicios de los 80, la memoria propendió por un olvido deliberado, manifestado en la amnistía promovida por Pinochet en 1978, que exoneró a todos los responsables de los crímenes de Estado. Después, entre 1983 y 1989 se observó una gran movilización social de diversos sectores, entre los que se encontraban las víctimas, sus familiares y las organizaciones constituidas para su defensa. Estos grupos se hacen escuchar en las calles, fusionando dos sentires: el de justicia a las víctimas y la desesperación por el impacto económico del neoliberalismo.

Desde 1990, con el proceso de democratización cobra importancia el esclarecimiento de las violaciones de los derechos humanos. Ese esfuerzo se materializó en la conformación de la Comisión Nacional de Verdad y Reconciliación, iniciativa que produjo como resultado un documento conocido como Informe Rettig. Asimismo, en el año 
2004, con el propósito de identificar a las personas que hubiesen sufrido privación de la libertad y tortura por razones políticas y de evitar el olvido y la impunidad, se conformó la Comisión Nacional sobre Prisión Política y Tortura, iniciativa que produjo un documento conocido como el Informe Valech.

Estos informes representan el posicionamiento de una contramemoria que rechaza la idea del golpe militar como salvación y reivindica la lucha incansable por lograr la justicia y la reparación. Es allí cuando los derechos humanos cobran importancia en relación con la memoria, estableciendo como objetivo común la garantía de los derechos. En esa lucha por posicionar una memoria distinta, ocupan un lugar destacado los monumentos y lugares de memoria edificados a lo largo y ancho del país.

En el caso de Colombia, las políticas de la memoria demuestran la complejidad de un contexto social y político que no ha logrado cerrar el conflicto. Según Vélez (2003):

Lo que no hay en Colombia es una acción política colectiva, que operacionalice o instrumentalice estas formas de recuperación de la memoria con el propósito de demandar la búsqueda de la verdad, la justicia y la reparación moral para los millares de asesinatos, secuestros, desapariciones y demás violaciones de derechos humanos. Cuando estas expresiones de recuperación de la memoria adquieren tal connotación, y cuando logran la atención de la opi- nión pública y del sistema judicial, son neutralizadas o eliminadas por quienes pueden resultar afectados con el esclarecimiento de los hechos o con la intervención de los jueces (p. 12).

A pesar de esto, en Colombia se han creado comisiones de verdad que, aunque no han tenido mucho impacto, sí han contribuido a la comprensión del conflicto armado y la violencia política en el ámbito académico, lo cual ha redundado en la elaboración de algunas políticas públicas. En el año 2000, producto de múltiples movilizaciones de carácter social, la memoria empieza a ganar un espacio en la agenda del gobierno, lo que deriva en la expedición de la ley 795 de 2005 (Ley de Justicia y Paz), en cuyo marco se creó la Comisión Nacional de Reparación y Reconciliación (CNRR) (Mejía, 2008, en Herrera y Pertuz, 2016, p. 167). Esta ley se expidió en una coyuntura política que buscaba la desmovilización de los grupos paramilitares durante el mandato de Álvaro Uribe Vélez. No obstante, esta ley produjo insatisfacción en amplios sectores de la sociedad, que reaccionaron en contra de ella y emprendieron una lucha política por visibilizar el lugar de las víctimas.

Resultado de las movilizaciones y del cambio de gobierno, que de nuevo le apuesta a una solución del conflicto por las vías del diálogo, se expidió en el año 2010 la ley 1408, por la cual se dictan medidas para la localización e identificación de víctimas del delito de desaparición forzada. Finalmente, en el año 2011 se expidió la ley 1448 (Ley de Víctimas y Restitución de Tierras), que encierra medidas de atención, asistencia y reparación integral de las 
víctimas del conflicto armado interno. A partir de la promulgación de estas políticas, la memoria empieza a ocupar un lugar en la academia, en los debates políticos y en el campo educativo, y las victimas empiezan a ser reconocidas en la vida pública, al ejercer un rol activo en diversos escenarios nacionales.

\section{Educar en derechos humanos para el "nunca más"}

La reiterada violación de derechos humanos en América Latina durante las dictaduras y los gobiernos que limitaron la democracia conllevó que durante los procesos de redemocratización se realizaran informes de verdad que ubicaron el tema de los derechos humanos como un punto fundamental en las agendas públicas $\mathrm{y}$ en las peticiones de las organizaciones sociales y de víctimas.

Así, los movimientos de derechos humanos de Argentina y Brasil de la década de 1980 empiezan a utilizar en sus consignas la expresión "nunca más" como un grito de rechazo a las atrocidades cometidas contra la población durante las dictaduras militares. Para Sacavino (2015): «El nunca más implica un esclarecimiento completo de lo sucedido bajo las dictaduras, como el correspondiente castigo a los responsables de las violaciones de derechos» (p. 71). Lo anterior permite visualizar el vínculo que se extiende entre memoria y derechos humanos. Es una relación de interdependencia en el sentido de que hablar de derechos humanos, tanto desde la vulneración como desde la necesidad de hacerlos respetar, implicaba recurrir al recuerdo de las víctimas, pero también de los victimarios, para esclarecer los crímenes, las torturas y las desapariciones.
Es así como la memoria desempeña un papel fundamental y un lugar de disputa en los escenarios públicos.

En la década de 1990, impulsada por diversas instituciones, a la educación (tanto en el campo formal como en las organizaciones comunitarias) se lleva la consigna "nunca más", como elemento fundamental dentro de los procesos de educación en derechos humanos. Del mismo modo, en 1999 se desarrolla el Seminario de Experiencias de Educación en Derechos Humanos, convocado por el Instituto Interamericano de Derechos Humanos, con sede en Costa Rica y Perú.. Allí se dieron cita importantes especialistas y defensores de los derechos humanos, quienes plantean la necesidad de educar en derechos humanos como una posibilidad para el restablecimiento de una sociedad democrática. Se plantearon entonces unos cambios educativos que implicaban:

La visión integral de los derechos humanos, una educación para el "nunca más", la puesta en marcha de procesos dirigidos a la formación de sujetos de derechos y actores sociales; y la promoción del empoderamiento individual y colectivo, especialmente, en el de los grupos sociales marginados o víctimas de discriminación (Candau, 2005, pp. 7-8, en Sacavino, 2015, p. 71).

Esta propuesta de formación hace mayor énfasis en los derechos colectivos y del ambiente, lo cual la diferencia de la propuesta neoliberal, centrada en 
el individualismo y en los derechos individuales civiles y políticos; además, ubica a la memoria en un lugar destacado y se opone al olvido promovido por algunas políticas de Estado; asimismo, propone recordar los horrores y vulneraciones, para motivar el coraje y la lucha hacia la exigencia de justicia y verdad y fortalecer el compromiso hacia la construcción de una sociedad donde sea posible el ejercicio democrático. La propuesta de empoderamiento individual y colectivo de los grupos marginados - las víctimassupone vincular la memoria a las luchas políticas, que no se quedan en el pasado, sino que se van actualizando en cada uno de los contextos. En palabras de Stern (2013), «hay diferentes formas de renovar la memoria, para las nuevas generaciones, esas que están hoy muy distantes de los hechos que ella evoca» (p. 6)

En esa tarea de actualizar la memoria es que se hace necesario el desarrollo de propuestas educativas centradas en la memoria de las comunidades que conlleven un reconocimiento de los niños, niñas y jóvenes como miembros de una sociedad afectada por la violencia política desde diversas perspectivas, para que ellos puedan asumir la tarea de conocerla y comprenderla, y formarse para transformarla.

Esa labor, que viene siendo asumida por los docentes de distintos niveles educativos por toda América Latina, es lo que la investigación pretende analizar en cuatro experiencias en Santiago de Chile y en cuatro en Bogotá, dirigiendo la mirada hacia tres aspectos fundamentales: a) las trayectorias de los sujetos maestros que han realizado apuestas por estos procesos de formación en derechos humanos; b) la forma como se logra vincular dicho tema a los currículos escolares, y c) la forma como se lleva a la práctica en las aulas.

\section{Metodología}

Este proceso investigativo se aborda desde un enfoque hermenéutico, en la medida que busca comprender las experiencias de $\mathrm{EDH}$, en donde se hallan inmersas innumerables acciones humanas, que son las que les dan cuerpo y sentido a las propuestas educativas. En tal sentido, se considera que la hermenéutica es un enfoque pertinente y adecuado para llevar a cabo el proceso investigativo, entendida como una concepción genérica sobre la realidad y el conocimiento que enfatiza en la comprensión del significado $y$, específicamente, en entender a la experiencia como significativa (De la Garza, 2000.Es así como: $<<$ La perspectiva hermenéutica se vincula con la de la subjetividad, entendida como proceso de producción de significados que puede analizarse en el plano individual o en el social $>>$ (Bourdieu, 1992, en De la Garza, 2000 p. 85). Sin embargo, los significados no solo se construyen por la interacción entre individuos, sino, también, dentro de ciertos límites espaciales y temporales.

En este sentido, se parte del hecho que la conducta humana, en este caso particular, la de los maestros educadores en derechos humanos, está animada por una intención. De allí que resulte pues necesario entender el proceso de interpretación y comprensión de esas acciones. Así, para Martínez (2011), comprender es:

Un encuentro de dos intencionalidades, la del sujeto conocedor y la del sujeto conocido; 
De la memoria a las memorias: Una reflexión teórico-metodológica en torno a la relación entre memoria y

quien dice comprensión, dice posibilidad de acceso a una vivencia psíquica que no es la nuestra, lo cual remite a una cierta forma de coexistencia con el prójimo, de vivencia vicaria, de alter ego (p. 105).

El círculo hermenéutico es la técnica sugerida por Dilthey, quien lo define como: «Un movimiento del pensamiento que va del todo a las partes y de las partes al todo» (p.98), de tal manera que aumente el nivel de comprensión, en un proceso dialéctico que no debe confundirse con el "círculo vicioso" de la lógica, en el que una cosa depende totalmente de la otra, y esta, a su vez, de la primera; el circulo hermenéutico, es más bien un "círculo virtuoso" (Martínez, 2011, p. 106).

A su vez, Paul Ricoeur desarrolló el modelo del texto para comprender el significado de la acción humana, a la que consideró como un texto literario que puede leerse para comprender a su autor, es decir, como un mecanismo para captar el significado que el autor puso en él. Según Ricoeur, la acción humana necesita objetivarse para convertirse en objeto de una ciencia humana, sin perder su carácter y riqueza de significación. Ricoeur indicó que las acciones dejan huellas en el tiempo, y que esas marcas pueden leerse; asimismo, señaló que la significación puede separarse de la intención del autor, y que produce consecuencias no intencionales. Por ello, es importante realizar una adecuada interpretación, que no se limite únicamente a la intención del autor.
Método biográfico

educación en derechos humanos.

Este método se sitúa en un marco conceptual ético y epistemológico; se forma como un enfoque interdisciplinario, que incluye influencias de la antropología, la sociología, la historia, la educación, la psicología, entre otras disciplinas y que reúne contribuciones de distintas corrientes de pensamiento: el estructuralismo, el marxismo, el existencialismo, la hermenéutica y el psicoanálisis.

Desde la perspectiva hermenéutica, los métodos biográficos cumplen una función identitaria.

"Según Ricoeur (1985),
se trata de una identidad
narrativa, que se construye
y reconstruye a través de
los relatos, los cuales dan
sentido a las acciones, a los
eventos vividos, restituyendo
un sentido global a un curso
caótico de una existencia. Al
hacer uso de un relato de vida
en una investigación y realizar
sobre este -o en un aspecto
de este- un análisis, se está
interpretando una producción
del narrador, que, a su vez,
es una interpretación de lo
que hace de su propia vida"
(Cornejo, Mendoza y Rojas,
2008).

Según los autores:

Esta "doble interpretación" (Ricoeur, 1983-1985) y los sucesivos niveles de trabajo analítico permiten introducir una distinción conceptual en- 
tre relato e historia de vida. El relato de vida corresponde a la enunciación - escrita $u$ oral- por parte de un narrador, de su vida o parte de ella. La historia de vida, por su parte, es una producción distinta, una interpretación que hace el investigador al reconstruir el relato en función de distintas categorías conceptuales, temporales, temáticas, entre otras. Esta distinción muestra la consistencia de la utilización de relatos de vida como método de investigación con su propio "objeto" de estudio, en tanto siempre se trabaja con interpretaciones, en distintos niveles. Interpretaciones que se consideran constituyentes de la experiencia humana y que, por tanto, representan la dimensión ontológica del enfoque biográfico (Cornejo, et al., 2008).

Este método será de gran importancia para la construcción de la trayectoria de los educadores. La noción de trayectoria que en la investigación se asume es la que Pierre Bourdieu (1997) propone y sobre la que el autor observa:

La noción de trayectoria como serie de posiciones sucesivamente ocupadas por un mismo agente (o un mismo grupo) en un espacio en sí mismo en movimiento y sometido a incesantes transformaciones. Tratar de comprender una vida como una serie única y suficiente en sí de acontecimientos sucesivos sin más vínculos que la asociación a un "sujeto" cuya constancia no es sin duda más que la de un nombre propio, es más o menos igual de absurdo que tratar de dar razón de un trayecto en el metro sin tener en cuenta la estructura de la red, es decir la matriz de las relaciones objetivas entre diferentes estaciones (p. 82).

De acuerdo con lo anterior, la construcción de las trayectorias de vida nos permite conocer las distintas posiciones y prácticas de los sujetos; la disponibilidad de los capitales sociales, culturales, simbólicos y económicos; los acontecimientos sociales e históricos que los han marcado; las aptitudes, y el posicionamiento en los diversos escenarios de acción.

Es importante aclarar que cuando se menciona que Bourdieu critica a la biografía, se refiere a dejar que sea el sujeto quien cuente lo que subjetivamente considera que debe ser conocido y no se está refiriendo al método biográfico, es decir, a los relatos de vida, pues se constituyen en un método de investigación que posibilita construir las trayectorias de los sujetos, trayectorias enfocadas en puntos específicos que el investigador desee resaltar.

\section{La discusión}

Como se ha venido desarrollando a lo largo del escrito, la investigación plantea una relación fuerte y necesaria entre memoria y educación en derechos humanos, en el contexto latinoamericano, desde 1990 hasta 
el presente. Ello cual implica develar las relaciones y acciones por parte del Estado y las organizaciones sociales para construir políticas de la memoria que incluyan a todos los miembros de la sociedad y que estén encaminadas al fortalecimiento de los derechos humanos.

No obstante, en este juego de intereses salen a relucir las memorias de los diversos sectores que pugnan por posicionarse en la esfera pública, y en ese campo de lucha, la educación en derechos humanos ocupa un lugar relevante. Desde luego, la postura de las instituciones y de los sujetos involucrados en los procesos formativos en derechos humanos marcan la diferencia.

\section{Conclusiones}

La educación en derechos humanos es un campo emergente donde se visualiza la disputa permanente entre las instituciones hegemónicas y aquellos grupos $\mathrm{y}$ movimientos sociales que han sido vulnerados, con el propósito de posesionar su discurso y llevarlo a los diversos escenarios, como la escuela, la ciudad y las organizaciones no gubernamentales. Sin embargo, cuando se habla de EDH, se asume una postura ético-política que va más allá de conocer los instrumentos propuestos por el sistema internacional de los derechos humanos. De hecho, implica asumirse desde una visión contrahegemónica que busca, desde las realidades locales y nacionales, develar la situación de permanente opresión y vulneración de las comunidades y aportar epistemológicamente a una visión de derechos humanos en la que se acoja a todos. Una EDH desde el sur, que establece un vínculo pasado-presente, relaciona la experiencia histórica (especialmente la de las violaciones de los derechos humanos) con las situaciones y problemáticas actuales, evalúa el avance o retroceso en el respeto y la promoción de los derechos humanos, plantea posibilidades de lucha y exigibilidad de los derechos, y no se queda en el lamento y el dolor de la víctima, pues empodera a los sujetos que fueron vulnerados, los forma como ciudadanos memoriales y emprende un camino de transformación.

Una educación en derechos humanos que promueva el "nunca más" debe estimular procesos de trabajo en torno a la memoria; al tiempo, debe mirar la historia desde la óptica y el ángulo de los vencidos, muchas veces invisibilizados; debe además otear la historia desde aquella mirada forjada por las prácticas de los movimientos sociales populares, por los diferentes grupos discriminados y subalternizados, por sus luchas por el reconocimiento y la conquista de sus derechos y ciudadanía en la vida cotidiana, y sus resistencias y su insistencia en producir otras maneras de ser, otras sensibilidades, otras percepciones para construir ciudadanía (Sacavino, 2000, p. 45), la cual debe ser una ciudadanía memorial, enmarcada en un sentido ético y político, que reconozca en el que sufre un otro que debe ser acogido, pero también un nosotros que se empodera y camina en colectivo hacia una sociedad más justa.

Finalmente, la EDH establece una estrecha relación con la memoria y la formación ciudadana, ya que el sentido de la educación en/para los derechos humanos se dirige hacia una transformación social mediante el desarrollo de una ciudadanía crítica, que promueve y exige sus derechos desde la movilización social y la consolidación de políticas públicas. 


\section{Referencias}

Augé, M. (1998). Las formas del olvido. Barcelona. Gedisa.

Bárcena, F. y Melich, J. (2011). La educación como acontecimiento ético. Natalidad, narración y hospitalidad. Barcelona: Paidós.

Bresciano, J. (2010). El tiempo presente como campo historiográfico. Montevideo: Ediciones Tradinco.

Bourdieu, P. (1997). La ilusión biográfica (anexo 1). En P. Bourdieu. Razones Prácticas. España: Anagrama.

Candau, J. (2001). Memoria e Identidad. Buenos Aires: Ediciones del Sol. (2006). Antropología de la memoria. Buenos Aires: Nueva Visión.

Cornejo, M., Mendoza, F. y Rojas, R. (2008). La investigación con relatos de vida: pistas y opciones del diseño metodológico. PSYKHE (Santiago), 17(1), pp. 29-39. Disponible en: https://scielo.conicyt.cl/scielo.php?script=sci arttext\&pid $=$ S0718-22282008000100004

Cuesta, J. (2008). La odisea de la memoria. Historia de la memoria en España siglo XX. Madrid: Alianza.

De la Garza, E. (2001). Subjetividad, Cultura. Clacso.

Dosse, F. (2012). El giro reflexivo de la historia. Recorridos epistemológicos y la atención a singularidades. Santiago de Chile: Ediciones Universidad Finis y Torrae.

Halbwachs, M. (2004). Los marcos sociales de la memoria. Barcelona: Antropos. . (2011). La memoria colectiva. Buenos Aires: Miño \& Dávila.
Hartog, F. (2003). Órdenes del tiempo, regímenes de historicidad. En F. Hartog. Regímenes de Historicidad. Presentismo y experiencias del tiempo (pp. 21-41). México: Universidad Iberoamericana. . (2012). El tiempo de las víctimas. Revista de Estudios sociales Numero 44.

Herrera, M. y Pertuz, C. (2016). Educación y políticas de la memoria en América Latina. Por una pedagogía más allá del paradigma del sujeto víctima. Bogotá: Universidad Pedagógica Nacional.

Martínez, M. (2011). Ciencia y arte en la metodología cualitativa. Métodos hermenéuticos, métodos fenomenológicos y métodos etnográficos. México; Trillas.

Nora, P. (s.f). Entre Memoria e Historia: La problemática de los lugares. Módulo virtual: Memorias de la violencia. Disponible en: http://comisionporlamemoria.org/bibliografia web/historia/Pierre.pdf

Ricoeur, P. (1985). Tiempo y narración. Argentina: Siglo XXI editores.

Ricoeur, P. (2008). La historia, la memoria y el olvido. México: Fondo de Cultura Económica.

Rioux, J. (1998). A memoria colectiva. En J. Rioux y J. Sirinelli. Para una historia cultural. Lisboa: Estampa.

Rodríguez A, S. (2013). Memoria y olvido. Usos políticos del pasado desde la Academia Colombiana de Historia 1930-1960. (Tesis de Doctorado). Universidad Nacional de Colombia, Bogotá, Colombia. Disponible en: https://www.academia.edu/8338249/ Memoria y olvido Usos $\mathrm{p} \% \mathrm{C} 3 \%$ BAblicos del pasado desde la Academia Colombiana de Historia 1930-1960 
Rubio, G (2012). El pasado reciente en la experiencia chilena. Bases para una pedagogía de la memoria. Estudios pedagógicos (Valdivia), 38(2), dic, pp. 375-396. Disponible en: https:// scielo.conicyt.cl/scielo.php?script $=$ sci arttext\&pid $=$ S0718-07052012000200023

Sacavino, S. (2000). Educar en derechos humanos y democracia. Rio de Janeiro: Novamerica.

Sacavino, S. (2015). Pedagogía de la memoria y educación para el "nunca más" para la construcción de la democracia. Folios, 41, pp. 69-82. Disponible en: http://revistas. pedagogica.edu.co/index.php/RF/article/ download/2946/2652.

Stern, S. (2013). Memorias en construcción, los retos del pasado presente en Chile 19982011. Santiago de Chile: Museo de la memoria $\mathrm{y}$ los derechos humanos.

Vélez R, J. (2003). Violencia, democracia y literatura testimonial en Colombia. Entre las memorias literales y las memorias ejemplares. Estudios Politicos, 22, pp. 31-57. Disponible en: http://aprendeenlinea.udea.edu.co/ revistas/index.php/estudiospoliticos/article/ view/17569/15146 